\title{
Tropical fishes killed by the cold
}

Received: 16 March 2008/Revised: 23 March 2008/Accepted: 25 March 2008/Published online: 9 April 2008 (C) Springer-Verlag 2008

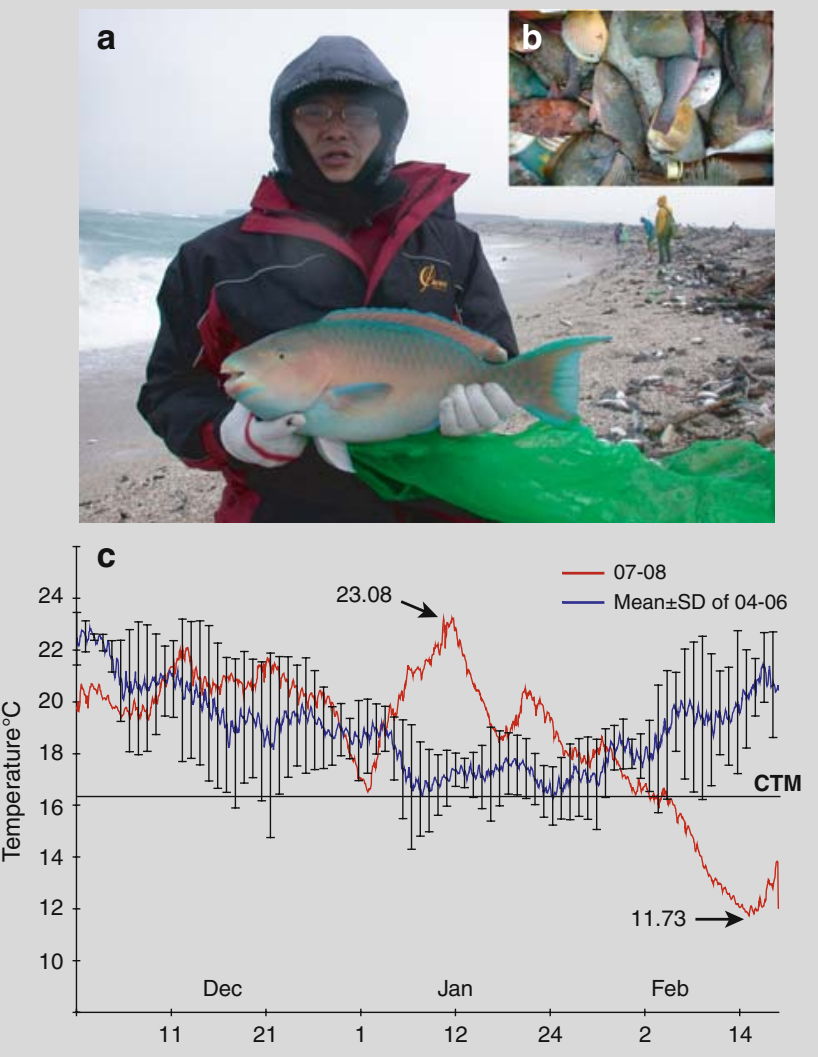

Fig. 1 (a) Fish collectors searching for high-priced fish on the Pescadores shore; (b) Close-up of dead reef fishes; (c) Hourly sea water temperatures December 2007-February 2008 at $3 \mathrm{~m}$ depth, Chinwan Inner Bay, Pescadores. CTM line, Critical thermal minimum for reef fishes (Mora and Ospina 2002)
In January 2008, a large number of coral reef fish were found washed ashore on the northern beaches at Pescadores $\left(23^{\circ} 10^{\prime}-50^{\prime} \mathrm{N} ; 119^{\circ} 20^{\prime}-50^{\prime} \mathrm{E}\right)$, a high-latitude coral community in the Taiwan Strait. The most abundant taxa were Diodon spp., Seranidae spp., Chaetodon spp., Labridae spp., Leiognathidae spp., ponyfishes, and Scarus spp. In total, 183 species of 58 families were recorded. However, the density of high-priced species, such as groupers, parrotfish, and wrasses were possibly underestimated due to prior intense collections by local residents (Fig. 1a). Macroinvertebrates were also killed, including echinoderms, crustaceans, mollusks, and corals.

These mortalities coincided with low temperature during the winter of 2007-2008. Data loggers at $3 \mathrm{~m}$ showed that seawater temperature was normal at $23.08^{\circ} \mathrm{C}$ on 12 January, but had fallen to $11.73^{\circ} \mathrm{C}$ by 15 February 2008 (Fig. 1c). The low temperature, large fluctuation, and 1 month long duration of the cold snap exceeded previous records between 2004 and 2007. The minimum temperature was well below the critical thermal minimum $\left(16.3^{\circ} \mathrm{C}\right)$ reported for some reef fish (Mora and Opsina 2002). Similar mass mortalities were also reported previously in 1977 and 1934 when air temperatures fell below $9^{\circ} \mathrm{C}$ (Tang 1978).

Acknowledgments We thank G-H Hong, A. Baird, D. Obura, H. Fukami, N. Knowlton, Academia Sinica Thematic Grant (20072009) and National Science Council grant (NSC95-2313-B-001022-MY3), Taiwan, to C.A.C. Evolutionary and Ecology Genetics of Coral Reef Group, RCBAS contribution no. 49.

\section{References}

Mora C, Ospina AF (2002) Experimental effect of cold, La Niña temperatures on the survival of reef fishes from Gorgona Island (east Pacific Ocean). Mar Biol 141:789-793

Tang HG (1978) The situations and reviews of the mass mortalities due to freeze during winter time in Pescadores. China Fish Mon 302:24-26 (in Chinese)

\section{H. J. Hsieh · Y.-L. Hsien - W.-S. Tsai}

Penghu Marine Biology Research Center, Fisheries Research Institute, Council of Agriculture, Penghu 880, Taiwan

H. J. Hsieh $(\bowtie) \cdot$ C. A. Chen

Institute of Oceanography, National Taiwan University, Taipei 106, Taiwan

e-mail: hernyi@ms15.hinet.net

W.-C. Su

Fisheries Research Institute, Council of Agriculture, Keelung 202, Taiwan

M.-S. Jeng · C. A. Chen ( $₫)$

Research Center for Biodiversity, Academia Sinica, Nankang, Taipei 115, Taiwan

e-mail: cac@gate.sinica.edu.tw 